\section{Cross-Sectional Analysis of Satsuma mandarin (Citrus unshiu Marc.) Consumption and Health Status Based on a Self-Administered Questionnaires}

\author{
Minoru Sugiura, * Hikaru Matsumoto, \\ and Masamichi Yano
}

Department of Citrus Research, National Institute of Fruit Tree Science, 485-6 Okitsu, Shimizu-shi, Shizuoka 424-0292, Japan (Received April 8, 2002; Accepted May 9, 2002)

Recently, the consumption of fruit has decreased or remained at the same level in Japan. It is possible that this may be due to a general mistaken connection between fruit consumption and the risks for diabetes, hyperlipemia, and obesity. This study is an evaluation of the hypothesis that a high-volume consumption of fruit might contribute to the same diseases. A crosssectional analysis was used to investigate the relationship between the frequency of Satsuma mandarin (Citrus unshiu Marc.) consumption and health status based on data from 6049 participants aged 20-79 years old on a self-administered questionnaire. After adjustments for age, sex, and body mass index, the odds ratios of risk for diabetes for participants consuming one to three pieces daily (middle consumption group) or more than four pieces daily (high consumption group) compared with those consuming fewer than three pieces a week (low consumption group) were 0.70 [95\% confidence interval $(\mathrm{CI}), \mathbf{0 . 5 9 - 0 . 8 3}$ ] and 0.48 (95\% CI, 0.41-0.58), respectively. On the other hand, the odds ratios of risk for hyperlipemia and obesity in the middle and high consumption groups compared with the low consumption group were not statistically significant. These results indicate the possibility that the consumption of Satsuma mandarin may act as a deterrent to diabetes and not be a risk factor for diabetes, hyperlipemia, and obesity.

Key words — Satsuma mandarin, fruit, diabetes, prevalence, cross-sectional study

\footnotetext{
*To whom correspondence should be addressed: Department of Citrus Research, National Institute of Fruit Tree Science, 485-6 Okitsu, Shimizu-shi, Shizuoka 424-0292, Japan. Tel.: +81-54369-7111; Fax: +81-543-69-2115; E-mail: msugiura@affrc.go.jp
}

\section{INTRODUCTION}

The value of fruit is considered to be equivalent to that of vegetables by health-conscious American and European consumers concerned with preventing such diseases as cancer, hypertension, and heart disease. ${ }^{1-5)}$ In the U.S.A., health authorities recommend a diet of five servings of fruit and vegetables each day. However, in Japan, fruit is given less attention than vegetables by the average consumer concerned with nutrition and disease prevention. Recently, the consumption of fruit has decreased or remained at the same level in Japan. ${ }^{6)}$ It is possible that this may be due to a general mistaken connection between fruit consumption and the risks for diabetes, hyperlipemia, and obesity. Youthful consumers are especially susceptible to this misunderstanding, and their consumption of fruit has recently been decreasing annually.

This study is an examination of the relationship between fruit consumption and the prevalence of diabetes, hyperlipemia, and obesity and an evaluation of the hypothesis that a high-volume consumption of fruit might contribute to those diseases. Specific attention was given to the consumption of Satsuma mandarin, which is the most frequently consumed domestic fruit in Japan. ${ }^{6}$ This survey was conducted in an area where Satsuma mandarin is considerably more popular than in the rest of Japan.

\section{MATERIALS AND METHODS}

The survey was undertaken in Shimizu, Mikkabi, and Gamagori, where Satsuma mandarin is popular. These cities are in the Tokai district, which is important for the production of Satsuma mandarin. The survey was administered to consumers who visited the Farmers Cooperative Society Festivals, which were held in Shimizu on November 24, 2000, Mikkabi on January 14, 2001, and Gamagori on February 25, 2001. All participants were residents. The self-administered survey sought information on sex, age, height, weight, and health status from all participants. Participants who indicated that they had health problems were asked to name any disease that had been diagnosed by physicians or recognized as a result of medical examinations. Specific attention was given to diabetes and hyperlipemia. Both of hypercholesteremia and hypertriglycemia were defined as hyperlipemia. There were no definite criteria for each disease, and this survey was based on 
Table 1. Frequency of Satsuma Mandarin Consumption in Each Age Group

\begin{tabular}{|c|c|c|c|c|c|c|c|c|c|c|}
\hline \multirow{3}{*}{$\frac{\text { Age group }}{20-29}$} & \multirow{3}{*}{$\frac{\text { Sex }}{\text { male }}$} & \multicolumn{8}{|c|}{ Level of consumption of Satsuma mandarin (No. of cases, \%) } & \multirow{3}{*}{$\begin{array}{c}\text { Total } \\
74\end{array}$} \\
\hline & & \multicolumn{2}{|r|}{1} & \multicolumn{2}{|c|}{2} & \multicolumn{2}{|c|}{3} & \multicolumn{2}{|c|}{4} & \\
\hline & & 11 & $(14.8)$ & 42 & $(56.8)$ & 18 & $(24.3)$ & 3 & $(4.1)$ & \\
\hline $30-39$ & male & 18 & $(8.2)$ & 125 & $(57.1)$ & 64 & $(29.2)$ & 12 & $(5.5)$ & 219 \\
\hline $40-49$ & male & 19 & $(6.5)$ & 153 & $(52.0)$ & 99 & $(33.7)$ & 23 & (7.8) & 294 \\
\hline $50-59$ & male & 17 & (3.0) & 252 & (44.4) & 247 & $(43.6)$ & 51 & $(9.0)$ & 567 \\
\hline $60-69$ & male & 10 & (1.5) & 204 & (30.9) & 357 & $(54.1)$ & 89 & (13.5) & 660 \\
\hline $70-79$ & male & 9 & (3.0) & 76 & $(25.0)$ & 179 & $(58.9)$ & 40 & $(13.2)$ & 304 \\
\hline $20-29$ & female & 15 & (8.9) & 98 & $(58.3)$ & 47 & $(28.0)$ & 8 & (4.8) & 168 \\
\hline 30-39 & female & 20 & $(4.2)$ & 232 & (48.9) & 190 & $(40.1)$ & 32 & $(6.8)$ & 474 \\
\hline $40-49$ & female & 16 & (3.2) & 175 & (34.9) & 253 & $(50.4)$ & 58 & (11.6) & 502 \\
\hline $50-59$ & female & 11 & $(0.8)$ & 261 & (19.2) & 823 & $(60.4)$ & 267 & (19.6) & 1362 \\
\hline $60-69$ & female & 15 & (1.4) & 137 & (12.8) & 708 & $(66.0)$ & 214 & (19.8) & 1074 \\
\hline $70-79$ & female & 4 & $(1.1)$ & 43 & (12.3) & 237 & $(67.5)$ & 67 & (19.1) & 351 \\
\hline \multirow[t]{2}{*}{ Total } & male & 84 & (4.0) & 852 & $(40.2)$ & 964 & (45.5) & 218 & (10.3) & 2118 \\
\hline & female & 81 & (2.1) & 946 & $(24.1)$ & 2258 & $(57.4)$ & 646 & (16.4) & 3931 \\
\hline Average age & male & \multirow{2}{*}{\multicolumn{2}{|c|}{$\begin{array}{l}47.17(15.10) \\
43.74(15.16)\end{array}$}} & \multirow{2}{*}{\multicolumn{2}{|c|}{$\begin{array}{l}52.24(13.03)^{a} \\
46.66(13.34)\end{array}$}} & \multirow{2}{*}{\multicolumn{2}{|c|}{$\begin{array}{l}58.73(11.80)^{a} \\
55.80(11.30)\end{array}$}} & \multirow{2}{*}{\multicolumn{2}{|c|}{$\begin{array}{l}59.28(11.09)^{a} \\
57.03(9.87)\end{array}$}} & $55.72(12.89)^{a}$ \\
\hline (S.D.) & female & & & & & & & & & $53.55(12.46)$ \\
\hline
\end{tabular}

Level 1, rarely eat; level 2, less than three a week; level 3, one to three daily; level 4, more than four daily. $a ; p<0.01$ vs female unpaired $t$-test

the self-reporting of participants. Four levels were used to ascertain the level of consumption of Satsuma mandarin during the peak of the season from October to February: level 1, "I rarely eat Satsuma mandarin"; level 2, "Although I sometimes eat Satsuma mandarin, I eat fewer than three a week"; level 3, "I eat one to three Satsuma mandarins daily"; and level 4, "I eat more than four Satsuma mandarins daily"

All survey participants were at least 20 years old. Individual body mass index (BMI: $\mathrm{kg} / \mathrm{m}^{2}$ ) was calculated from height and weight. A BMI of 26.4 and above is considered to be an indicator of obesity. The odds ratios of diabetes and hyperlipemia prevalence were statistically analyzed according to the level of Satsuma mandarin consumption after adjustments for age, sex, and BMI using multiple logistic regression analysis and $95 \%$ confidence intervals were determined. In the case of obesity, the odds ratios were analyzed after adjustments for age and sex.

\section{RESULTS}

A total of 6049 survey responses were obtained (2118 men and 3931 women) (Table 1). The collection rate was $69.6 \%$. Among all respondents, $71.4 \%$ were over 50 years of age. The average age for each consumption level of Satsuma mandarin shows in Table 1. In levels 2, 3, and 4, the mean age of men were statistically significantly higher than that of women. Among the male participants, $50 \%$ or more of those less than 50 years old ate fewer than three Satsuma mandarins weekly. On the other hand, 50\% or more of women over 40 years old ate Satsuma mandarins daily.

The prevalence rates of diabetes, hyperlipemia, and obesity were especially high in participants of either sex who were more than 50 years of age. The exceptions were hyperlipemia and obesity among men (Table 2). Because the group that rarely ate Satsuma mandarin was limited to 165 participants, it was combined with the level 2 group, who ate fewer than three weekly, to form a low consumption group. The odds ratios for the prevalence of diabetes were significantly lower in the middle and high consumption groups (Table 3). On the other hand, the odds ratios of hyperlipemia and obesity did not differ in middle and high consumption groups (Table 3). Furthermore, participants who indicated they had diabetes were also asked if they restricted their fruit intake. Although the reply rate to the question was only $30.2 \%, 91.1 \%$ of those who replied ate one or two pieces of fruit every day even if they had diabetes. The number of participants who indi- 
Table 2. Prevalence Rate of Each Disease Among All Participants in Each Age Group

\begin{tabular}{ccccc}
\hline \hline & & \multicolumn{3}{c}{ Prevalence rate (\%) } \\
\cline { 3 - 5 } Age group & Sex & Diabetes & Hyperlipemia & Obesity \\
\hline 20-29 & male & 1.35 & 1.35 & 9.46 \\
30-39 & male & 1.83 & 12.79 & 11.87 \\
40-49 & male & 5.78 & 19.39 & 14.29 \\
50-59 & male & 11.46 & 22.93 & 8.64 \\
$60-69$ & male & 11.51 & 18.03 & 7.42 \\
$70-79$ & male & 10.53 & 16.78 & 6.91 \\
& & & & \\
20-29 & female & 0.60 & 1.79 & 2.38 \\
30-39 & female & 0.42 & 3.81 & 1.91 \\
$40-49$ & female & 1.20 & 9.16 & 3.98 \\
$50-59$ & female & 3.89 & 23.94 & 5.65 \\
$60-69$ & female & 5.21 & 26.07 & 8.19 \\
$70-79$ & female & 6.27 & 22.22 & 7.98 \\
& & & 18.22 & 9.16 \\
Total & male & 9.21 & 19.10 & 5.75 \\
& female & 3.56 & &
\end{tabular}

cated that they did not eat Satsuma mandarin because they had diabetes was extremely small $(8.9 \%$ of those who replied).

\section{DISCUSSION}

In this study, we examined the hypothesis that a high-volume consumption of fruit might contribute to diabetes, hyperlipemia, and obesity. Consumption of fruit is most likely flagging in Japan because consumers do not understand its preventive effects against cancer, hypertension, and heart disease. Furthermore, it is also conceivable that consumers believe that fruit is generally high in calories and is therefore a risk factor for diabetes, hyperlipemia, and obesity. However, one Satsuma mandarin (about $100 \mathrm{~g}$ ) has $10 \mathrm{~g}$ of carbohydrates and a total of 35$40 \mathrm{kcal}$. In addition to the carbohydrates, the fruit contains numerous vitamins, carotenoids, and minerals. Based on the calorie count and nutrients of Satsuma mandarin, it would be difficult to think that a sensible level of consumption could contribute to diabetes, hyperlipemia, or obesity; however, it would be unfavorable to consume too much of the fruit. In this cross-sectional study, the results showed that the odds ratios of hyperlipemia and obesity were not high in the middle and high consumption groups (Table 3). Furthermore, the odds ratios of diabetes were significantly low in the middle and high consumption groups (Table 3). These results indicate the possibility that the consumption of Satsuma mandarin may act as a deterrent to the development of diabetes, rather than as a risk factor for diabetes, hyperlipemia, and obesity. Recent epidemiologic studies have shown that the blood concentrations of vitamin $\mathrm{E}$ and carotenoids in diabetes patients were significantly lower than in healthy individuals. ${ }^{7,8)}$ These results suggest that fruit is effective in the prevention of diabetes because it is including vitamins and carotenoids abundantly.

In our survey, most participants were probably interested in farm products such as fruit and vegetables and were generally healthy. We are not able to overcome the problem of selection bias in our survey because certain demographics, such as job or place of residence area, were not clear. Furthermore, we used the data from self-administered questionnaires. To our knowledge, there have been no reports on whether the data from self-administered

Table 3. Odds Ratios for Satsuma Mandarin Consumption and Diseases Prevalence Among 6049 Participants Aged 20-79 Years Old

\begin{tabular}{lllll}
\hline \hline \multirow{2}{*}{$\begin{array}{l}\text { Frequency of Satsuma } \\
\text { mandarin consumption }\end{array}$} & & \multicolumn{3}{c}{ Odds ratio (95\% confidence interval) $^{a}$} \\
\cline { 2 - 4 } Male & Low & \multicolumn{1}{c}{ Diabetes $^{b}$} & Hyperlipemia $^{b}$ & Obesity $^{c}$ \\
& Middle & 1.00 & 1.00 & 1.00 \\
& High & $0.70(0.56-0.87)$ & $1.00(0.77-1.29)$ & $1.06(0.85-1.31)$ \\
Female & $0.49(0.39-0.61)$ & $0.99(0.77-1.29)$ & $1.12(0.90-1.38)$ \\
& Low & 1.00 & 1.00 & 1.00 \\
& Middle & $0.70(0.53-0.91)$ & $1.00(0.93-1.07)$ & $0.94(0.76-1.16)$ \\
Male and Female & High & $0.48(0.37-0.63)$ & $1.00(0.93-1.07)$ & $0.88(0.71-1.09)$ \\
& Low & 1.00 & 1.00 & 1.00 \\
& Middle & $0.70(0.59-0.83)$ & $1.00(0.92-1.08)$ & $0.99(0.94-1.06)$ \\
& High & $0.48(0.41-0.58)$ & $0.99(0.92-1.08)$ & $0.99(0.93-1.05)$ \\
\hline
\end{tabular}

$a$; Low, less than three a week; middle, one to three daily; high, more than four daily. $b$; Adjusted for age and sex (except sex-specific model), and body mass index. $c$; Adjusted for age and sex (except sex-specific model). 
questionnaire are effective in the measurement of disease prevalence. It is conceivable that many participants did not realize that they had diabetes or hyperlipemia because they had not undergone medical examination. In addition, BMI may not be reflect true values because we calculated BMI using high and weight given on the self-administered questionnaires. We are planning to further investigations to clarify whether our results in this study correlate with an actual disease prevalence.

Many epidemiologic studies investigating the causes of diabetes have focused on risk factors such as BMI, hyperlipemia, hypertension, exercise, calorie and fat consumption, family history, and alcohol consumption. ${ }^{9-14)}$ However, our study was limited to age, sex, BMI, and the frequency of Satsuma mandarin consumption. It is conceivable people who consume Satsuma mandarins frequently are healthy or have healthy eating habits. Follow-up studies are necessary for a more detailed analysis of the relationships among another confounding factors and diabetes. Furthermore, there are limits in estimating causality between Satsuma mandarin consumption and disease prevalence in a cross-sectional study. We need to clarify the relationship between Satsuma mandarin consumption and disease incidence in further prospective cohort or intervention studies.

\section{REFERENCES}

1) Agarwal, S. and Rao, A. V. (2000) Carotenoids and chronic diseases. Drug Metabol. Drug Interact, 17, 189-210.

2) Van Duyn, M. A. and Pivonka, E. (2000) Overview of the health benefits of fruit and vegetable consumption for the dietetics professional: selected literature. J. Am. Diet. Assoc., 100, 1511-1521.

3) Feldman, E. B. (2001) Fruits and vegetables and risk of stroke. Nutr. Rev., 59, 24-27.

4) Hooper, L. (2001) Dietetic guidelines: diet in secondary prevention of cardiovascular disease. $J$. Hum. Nutr. Diet., 14, 297-305.

5) Terry, P., Terry, J. B. and Wolk, A. (2001) Fruit and vegetable consumption in the prevention of cancer: an update. J. Intern. Med., 250, 280-290.

6) Statistics Bureau \& Statistics Center of the Ministry of Public Management, Home Affairs, Post and Telecommunications (2000) Family income and expenditure survey report.

7) Salonen, J. T., Nyyssonen, K., Tuomainen, T. P., Maenpaa, P. H., Korpela, H., Kaplan, G. A., Lynch, J., Helmrich, S. P. and Salonen, R. (1995) Increased risk of non-insulin dependent diabetes mellitus at low plasma vitamin E concentrations: a four year follow up study in men. BMJ, 311, 1124-1127.

8) Ford, E. S., Will, J. C., Bowman, B. A. and Narayan, K. M. (1999) Diabetes mellitus and serum carotenoids: Findings from the Third National Health and Nutrition Examination Survey. Am. J. Epidemiol., 149, 168-176.

9) Nelson, R. G., Enverhart, J. E., Knowler, W. C. and Bennett, P. H. (1988) Incidence, prevalence and risk factors for non-insulin-dependent diabetes mellitus. Prim. Care, 15, 227-250.

10) Manson, J. E., Rimm, E. B., Stampfer, M. J., Colditz, G. A., Willett, W. C., Krolewski, A. S., Rosner, B. Hennekens, C. H. and Speizer, F. E. (1991) Physical activity and incidence of non-insulin-dependent diabetes mellitus in women. Lancet, 338, 774-778.

11) Fujimoto, W. Y., Bergstrom, R. W., Boyko, E. J., Kinyoun, J. L., Leonetti, D. L., Newell-Morris, L. L., Robinson, L. R., Shuman, W. P., Stolov, W. C. and Tsunehara, C. H. (1994) Diabetes and diabetes risk factors in second- and third-generation Japanese Americans in Seattle, Washington. Diabetes Res. Clin. Pract., 24(Suppl.), S43-S52.

12) Marshall, J. A., Hoag, S., Shetterly, S. and Hamman, R. F. (1994) Dietary fat predicts conversion from impaired glucose tolerance to NIDDM. The San Luis Valley Diabetes Study. Diabetes Care, 17, 50-56.

13) Monterrosa, A. E., Haffner, S. M., Stern, M. P. and Hazuda, H. P. (1995) Sex differences in lifestyle factors predictive of diabetes in Mexican-Americans. Diabetes Care, 18, 448-456.

14) Pan, X. R., Yang, W. Y., Li, G. W. and Liu, J. (1997) Prevalence of diabetes and its risk factors in China, 1994. National Diabetes Prevention and Control Cooperative Group. Diabetes Care, 20, 1664-1669. 